\title{
SEMIOSES ACIONAIS NA JOGABILIDADE DE UM : JOGO MÓVEL DE LOCALIZAÇÃO
}

\section{ACTION SEMIOSIS IN LOCATION-BASED GAMEPLAY}

\author{
Raquel Salcedo Gomes ${ }^{1}$ \\ Universidade Federal do Rio Grande do Sul
}

Cleci Maraschin ${ }^{2}$

Universidade Federal do Rio Grande do Sul

\section{RESUMO}

Nos estudos de videogame, jogabilidade é um conceito central, porém controverso. Mello (2013) propõe um conceito de jogabilidade que integra as características de interface, agência e interação, em uma tentativa de não reduzi-lo a apenas um aspecto, contemplando design, mecânica e a experiência de jogar. Considerando a sistematização de Mello (2013), tomamos jogabilidade como o conjunto de características que permitem compreender um artefato semiótico-interacional como jogo, da mesma forma que, em semiótica, a textualidade é concebida como o caráter que possibilita denominar um artefato semiótico de texto. Partindo desse pressuposto, propomos uma análise semiótica da interface da jogabilidade de um jogo móvel de localização elaborado para ser jogado com dispositivos móveis no Jardim Botânico de Porto Alegre, RS. A metodologia de análise contemplou o percurso gerativo de sentido (GREIMAS e COURTÊS, 2008; BARROS, 2005), nos níveis fundamental, narrativo e discursivo da jogabilidade, considerando categorias da semiótica plástica (GREIMAS, 2004) e atentando para suas características de design na tela do dispositivo móvel. A análise apontou para a construção semântico-narrativo-discursiva do jogo como intimamente atrelada aos espaços físicos do parque, o que pode proporcionar multiletramentos em uma perspectiva acional, com ênfases

1 Doutoranda em Informática na Educação pela Universidade Federal do Rio Grande do Sul. Mestre em Linguística Aplicada pela Universidade do Vale do Rio dos Sinos. E-mail: salcedogomes@ gmail.com.

2 Professora dos Programas de Pós-Graduação em Informática na Educação e Psicologia Social e Institucional da Universidade Federal do Rio Grande do Sul. Doutora em Educação. E-mail: cleci. maraschin@gmail.com. 
nas práticas desenvolvidas na experiência do jogar, privilegiando jogadores com realçadas características cinestésicas em seus processos de : aprendizagem.

PALAVRAS-CHAVE: Jogabilidade; Jogo Móvel Locativo; Semiótica; Multiletramentos.

\section{ABSTRACT}

In video game studies, gameplay is a central concept, however controversial. Mello (2013) proposed a concept of gameplay that integrates the features of interface, agency and interaction, in an attempt not to narrow it down to just one aspect, covering design, mechanics and the experience of playing. Considering the systematization of Mello (2013), we conceive of gameplay as the set of features that allow us to understand a semiotic-interactional artifact as a game, just like, in semiotics, textuality is conceived as the character that enables calling a semiotic artifact a text. Based on this assumption, we propose a semiotic analysis of the gameplay interface of a location-based game designed to be played with mobile devices in the Botanical Garden of Porto Alegre, RS. The analysis methodology included the generative course of meaning (GREIMAS e COURTÊS, 2008; BARROS, 2005), in the fundamental, narrative and discursive levels of gameplay, considering categories of plastic semiotics (GREIMAS, 2004) and focusing on its design features on the mobile gadget screen. The analysis pointed to the semantic-narrative-discursive construction of the game as closely linked to physical spaces of the park, which can provide multiliteracies in an active perspective, with emphasis on practices developed in the experience of playing, favoring players with enhanced kinesthetic features in their learning processes.

KEYWORDS: Gameplay; Location-Based Game; Semiotics; Multiliteracies.

\section{INTRODUÇÃO}

Nos estudos de videogame, jogabilidade ou, originalmente, gameplay, é um conceito central, porém controverso (MELLO, 2013; ROLLINGS \& ADAMS, 2003). Alguns autores concebem jogabilidade como a experiência 
: lúdica do jogador e suas expectativas junto aos desafios impostos pelo : jogo; outros consideram que o conceito remete apenas à engenharia das ações possíveis, excluindo a subjetividade do jogador, ao passo que há ainda pesquisadores que relacionam jogabilidade somente com o design do jogo. Mello (2013), que inspirou nossa definição do conceito, propõe que a jogabilidade integra, nos jogos, as características de interface, agência e interação, em uma tentativa de não reduzir o conceito a apenas um aspecto, contemplando assim design, mecânica e a experiência de jogar. Considerando o empreendimento sistematizador de Mello (2013), neste trabalho, tomamos jogabilidade como o conjunto de características que permitem compreender um artefato semiótico como jogo, da mesma forma que, em semiótica, a textualidade é concebida como o caráter que possibilita denominar um artefato semiótico de texto.

Partindo desse pressuposto, e norteadas pela questão "Qual é o percurso gerativo de sentido da jogabilidade do jogo móvel de localização Um Dia no Jardim Botânico?”, propomos uma análise semiótica (GREIMAS e COURTÊS, 2008) da jogabilidade em um jogo móvel de localização elaborado para ser jogado com dispositivos móveis no Jardim Botânico de Porto Alegre, RS. Jogos móveis de localização são jogos digitais vinculados a um espaço físico. Também chamados de pervasivos (BENFORD et al., 2005), eles aliam tecnologias móveis a sistemas de geolocalização, criando, segundo Lemos (2010), interfaces entre os espaços eletrônico e físico para fins de jogo. O jogo, denominado Um Dia no Jardim Botâncio, cuja tela inicial pode-se visualizar abaixo na Figura 1, está sendo desenvolvido pelo grupo de pesquisa Ecologias e Políticas Cognitivas (NUCOGS), da Universidade Federal do Rio Grande do Sul, e integra o projeto Oficinando em Rede: processos de aprendizagem e jogos locativos, cujo objetivo maior é o mapeamento dos processos de aprendizagem experimentados em seu transcurso (MARASCHIN, 2013).

Inserida neste projeto, a presente pesquisa debruça-se sobre os letramentos multisemióticos fomentados pela experiência de jogar. Nessa direção, cremos que uma análise semiótica da interface da jogabilidade, evidenciando as linguagens verbais e não verbais em interação na composição do artefato, articula uma etapa importante da pesquisa, desenvolvida a partir de uma perspectiva atorrediana de investigação (LATOUR, 2012), esta, por sua vez, bastante influenciada pela semiótica discursiva de matriz francesa. 


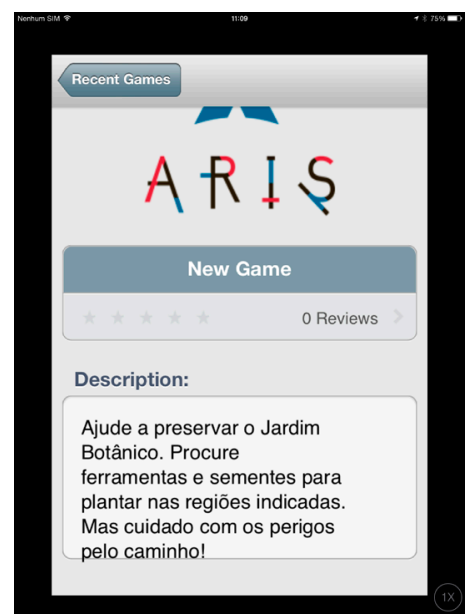

Figura 1 - Tela inicial do jogo móvel locativo

Um Dia no Jardim Botânico

Fonte - Captura de tela pelas autoras

A teoria ator-rede busca desmanchar dicotomias consolidadas a partir dos desdobramentos metodológicos e analíticos das revoluções científica e industrial que constituíram a modernidade, propondo um ponto de vista filosófico-antropológico de acompanhamento dos processos culturais nos diferentes contextos, tendo na simetria sua proposição política. No âmbito desta pesquisa, buscamos instaurar olhares não-dicotomizados, sobre os modos de existência das tecnologias em contextos educacionais de aprendizagem.

A fim de dar procedimento ao enfoque objetivado neste artigo, iniciamos com uma discussão sobre o conceito de jogabilidade, seguida pela apresentação do conceito de letramento e as transformações por que esse último tem passado devido a mudanças nas práticas sociolinguageiras influenciadas pelas tecnologias digitais. Procedemos então à análise semiótica do jogo móvel de localização, discorrendo, por fim, sobre as multisemioses potentes a partir dele, balizadas pelas noções de interface, agência e interação. 


\section{Jogabilidade}

Poucas vezes definido nas publicações especializadas (VANNUCCHI \& PRADO, 2010), o conceito de jogabilidade é essencial para a compreensão de um artefato semiótico cultural como jogo (ASSIS, 2007), principalmente nesta época transmidiática de liquidez tecnológica entre os objetos culturais. Vannucchi e Prado (2010, p. 131) consideram que as definições mais comuns relacionam jogabilidade à "virtude que um jogo possui para ser fácil e intuitivo de jogar", incentivando a adesão do jogador.

De acordo com Mello (2013), não existe um referencial acadêmico considerado pacífico na definição. Alguns autores concebem jogabilidade como a experiência lúdica do jogador (FEIL \& SCATTERGOOD, 2005) e suas expectativas junto aos desafios impostos pelo jogo (HOWLAND, 1999); outros consideram que o conceito remete apenas à engenharia das ações possíveis, a mecânica do jogo (SICART, 2008), excluindo a subjetividade do jogador, ao passo que há ainda pesquisadores que relacionam jogabilidade somente com design.

Embora ausente de dicionários de língua portuguesa, em língua inglesa gameplay está presente no Longman Dictionary of Contemporary English e no English Collins Dictionary, conceituada como "o modo como um jogo de computador é projetado e as habilidades necessárias para jogálo" (VANNUCCHI \& PRADO, 2010, p. 131). Para Rollings e Adams (2003, p. 200), gameplay constitui-se de "uma ou mais séries de desafios em uma relação causal, num ambiente de simulação", que "incentiva o jogador a empregar estratégias" (p. 201) para atuar no jogo.

Para Lindley (2002), gameplay diz respeito às atividades possíveis de serem realizadas no quadro de regras do jogo, que contribuem, direta ou indiretamente, para o alcance de metas. Arsenault e Perron (2009) relacionam gameplay ao encontro do jogo com o jogador e sua interação, aproximandose ao modelo teórico de Heaton (2006), que demonstra o gameplay como uma interação randômica, com um fluxo circular de informação entre o humano e o não humano.

Tais possibilidades conceituais amparam uma correlação entre jogos eletrônicos e aprendizagem, visto que eles proporcionam um conjunto de desafios em uma teia de problematizações. Esses desafios demandam o desenvolvimento de estratégias de ação no alcance de objetivos, o que remete 
à compreensão das regulações estabelecidas pelos componentes semióticos do jogo e impulsiona a construção de saberes sobre sua interface, o modo como jogo atua sobre o jogador e vice-versa, instaurando a interação entre ambos.

Na tentativa de abrigar essas múltiplas ênfases, Mello (2013) propõe um conceito emergente em direção à complexidade, explicando jogabilidade como a reunião das características de interface, agência e interação. Interface refere-se ao modo como o jogo se apresenta ao jogador, engaja-o à sua narrativa, o incentiva a aderir a seus objetivos e realizar leituras sobre possíveis formas de intervenção mediante uma série de semioses. Agência diz respeito às regras que o jogo impõe, balizando discursos e ações, aproximando ou afastando o jogador das metas do jogo pela presença sequencial de orientações que o ajudam ou pela interposição de obstáculos que o atrasam e exigem estratégias alternativas, quebrando a linearidade a fim de superá-las. Interação, por sua vez, relaciona-se às construções semiótico-acionais desdobradas a partir dos modos como jogo e jogador impõem, um ao outro, formas de continuidade e descontinuidade. Pode-se dizer que não há jogo sem interação, pois, a fim de que o jogo se atualize, isto é, adentre o campo da existência, deixando de ser apenas potência e virtualidade, é necessária a interação com o jogador para que o jogo seja enunciado, concretizado, trazido ao campo da materialidade, dotado de sentido.

A conceituação tripartida de Mello (2013) nos remete ao entendimento da jogabilidade como experiência (VANNUCCHI \& PRADO, 2010), como acontecimento vivenciado no tempo e no espaço em um quadro comunicacional contextualizado, o qual compõe uma história e institui vivências que contribuem para o desenvolvimento de problematizações, o estabelecimento de associações e a construção de conceitos, modulando aprendizagens.

Nesse sentido, consideramos que a jogabilidade pode emoldurar certas formas de letramento, uma vez que exige o desenvolvimento de habilidades múltiplas, as quais envolvem semioses em práticas socioculturalmente atreladas à experiência de jogar. Tomando tal enquadramento da jogabilidade, discorremos sobre letramentos e seus desdobramentos em multiletramentos no âmbito dos jogos eletrônicos. 


\section{De um letramento aos multiletramentos}

A noção de letramento surgiu na tentativa de complementar o conceito de alfabetização. Enquanto essa última significa a aprendizagem e o desenvolvimento de habilidades relativas ao reconhecimento e uso do sistema linguístico, vinculando-se a seus aspectos formais, o conceito de letramento busca ampliar aprendizagens relacionadas à língua, abrigando linguagens, discursos, funções pragmáticas e práticas socioculturais em que estas estão inseridas.

Soares (1999, p. 3), por exemplo, concebe letramento como "estado ou condição de quem não só sabe ler e escrever, mas exerce as práticas de leitura e escrita que circulam na sociedade em que vive, conjugandoas". Outro autor que traz luz ao conceito de letramento é Britto (2003), relacionando-o a avanços no modo de compreender as relações interhumanas, os processos de participação social e os modos de construção do conhecimento. Ele reitera que letramento tem sido concebido mais na relação com as práticas sociais de uso da escrita e da leitura do que os termos alfabetização ou alfabetismo.

Britto (2003) relata que há concepções de letramento como processo pelo qual se estabelece a distribuição dos saberes formais e outras concepções de letramento como estado de indivíduos ou grupos no que se refere às competências de ler e escrever como modos de atuar em espaços sociais. Abrindo caminho para o desenvolvimento da noção de letramento digital, Britto (2003, p. 13) postula que, estando relacionado com modos de escolarização e com os processos de produção e difusão da cultura escrita, o letramento não deve ser considerado terreno exclusivo da área da linguagem, nem transformado em área do conhecimento ou matéria escolar. Ele envolve o fazer do sujeito e articula as dimensões da técnica e da política na experiência existencial, o que incide também nos usos e nas concepções acerca das tecnologias digitais.

Jung (2007) denuncia e desmistifica uma série de questões que historicamente foram associadas à ideia do ser letrado. Segundo ela, houve posicionamentos que relacionam o letramento à capacidade cognitiva e até mesmo à postura ética dos indivíduos, associando o conceito à bondade moral, posicionamentos que construíram uma espécie de "mito do letramento" (KLEIMAN, 1995 apud JUNG, 2007, p. 85), conferindo-lhe 
um tipo de poder como tecnologia neutra disponível para o progresso e desenvolvimento tanto do indivíduo quanto da coletividade, algo similar ao : que ocorre com pontos de vista salvacionistas sobre as tecnologias digitais.

Tfouni (1995, p. 20) afirma que o "letramento focaliza os aspectos sócio-históricos da aquisição de um sistema escrito por uma sociedade". Com o advento da tela digital como espaço de escrita, mudanças significativas vêm ocorrendo nas formas de interação entre escritor e leitor, entre ser humano e conhecimento e nas formas de composição dos textos e demais artefatos semióticos. Concordando com diversos autores, dos quais destacam-se em seu texto as ideias de Pierre Lévy, Soares (2002) crê que essas mudanças têm consequências sociais, cognitivas e discursivas, configurando um letramento digital, ou seja,

um certo estado ou condição que adquirem os que se apropriam da nova tecnologia digital e exercem práticas de leitura e de escrita na tela, diferente do estado ou condição - do letramento - dos que exercem práticas de leitura e de escrita no papel. (SOARES, 2002, p. 151)

Marcuschi (2005) afirma que os principais desafios nos usos linguísticos das tecnologias residem nos aspectos relativos às novas estratégias de comunicação e às formas de uso, que se diversificam tanto na escrita como nas relações. O autor afirma a necessidade de uma nova gramática de interação e compreensão desses usos do que propriamente dos modos de escrita da gramática das formas linguísticas nesse contexto. Para ele, "há diversos desafios cognitivos, no acúmulo de informações e na necessidade de maior formação para enfrentar problemas de compreensão" (MARCUSCHI, 2005, p. 10).

Conforme Marcuschi, o letramento digital dedica-se ao ensino dos usos da internet, isto é, "ao modo como lidamos socialmente com a escrita digital" (2005, p. 11). Discordamos dele quando afirma que "quem mais se modifica com isto não é nem a linguagem nem a natureza do ensino, mas sim a natureza das atividades interativas e cognitivas pelas novas formas de uso da linguagem" (MARCUSCHI, 2005, p. 12). Acreditamos que, além das atividades cognitivas e interativas, a linguagem sofre modificações sim, pois um sistema semiótico acaba por influir nos modos de expressão e enunciação dos demais (conf. GOMES, 2013). 
Nesse sentido, Xavier (2002, p. 2) afirma que

ser letrado digital pressupõe assumir mudanças nos modos de ler e escrever os códigos e sinais verbais e não-verbais, como imagens e desenhos, se compararmos às formas de leitura e escrita feitas no livro, até porque o suporte sobre o qual estão os textos digitais é a tela, também digital.

Para ele, "somente o letrado alfabético tem condições de se apropriar totalmente do letramento digital, pois os conhecimentos necessários para entender e acompanhar já foram apreendidos" (XAVIER, 2002, p. 5). Concordamos parcialmente com ele no que concerne a uma apropriação idealizada e logocêntrica dos usos da escrita no meio digital, mas enfatizamos que a tecnologia digital preconiza uma usabilidade intuitiva dos softwares e hipertextos, além de que, devido a seu caráter muitas vezes formulaico (MARCUSCHI, 2005), não requer sempre conhecimento profundo do mundo das letras, seus gêneros e estilos para ser utilizada.

Do letramento para além do letramento digital, Cope e Kalantzis (2006, p. 18) propõem uma perspectiva de multiletramentos, à qual subjaz "uma epistemologia do pluralismo, que viabiliza acesso, sem que as pessoas precisem apagar ou deixar para trás suas diferentes subjetividades". As práticas multiletradas se originaram com as "mudanças sociais, culturais e tecnológicas advindas da era do ciberespaço" (DIAS, 2012, p. 8). Assim, interagir em espaços multiletrados implica lidar com a multimodalidade textual, com multisemioses, isto é, com a capacidade de ler e produzir a partir de artefatos que combinam diferentes modos semióticos, desde o linguístico ao imagético, sonoro, gestual e espacial (WALSH, 2010), e de agir de maneira crítico-reflexiva frente à diversidade. Segundo Rojo (2012), o termo multiletramentos difere do conceito de letramento(s) por este se referir à multiplicidade e variedade das práticas letradas da nossa sociedade e aquele fazer referência tanto à multiplicidade cultural quanto à semiótica de constituição dos textos-artefatos.

Considerando tais fluxos de multiplicidades, destacamos, na atualidade, a interface das telas digitais, que conjugam práticas sociais de interação com os vários sistemas semióticos, dispostos hipertextualmente e em relação a valores, regras, técnicas, dimensões sociais e subjetivas, éticas e 
políticas aí implicados. Assim, munidas desse referencial teórico, propomos uma aproximação entre jogabilidade e multiletramentos na interface de um jogo móvel de localização, debruçando-nos sobre seu sincretismo de linguagens e as diversas possibilidades de sentido, estratégias e ações que pode produzir na experiência de jogar e ensejar processos de aprendizagem.

\section{Jogos móveis locativos e multisemioses: Um Dia no Jardim Botânico}

O jogo Um Dia no Jardim Botânico foi desenvolvido na plataforma ARIS (Augmented Reality and Interactive Storytelling), que consiste em uma ferramenta de código aberto para a produção de "experiências educacionais locativas e interativas, centradas na narrativa" (GAGNON, 2010). A plataforma utiliza tecnologia GPS para criar e reproduzir jogos, passeios e histórias, proporcionando aos jogadores vivências em um ambiente híbrido de personagens interativos virtuais, itens e meios de comunicação em um espaço físico (GAVILLON, 2014). Retomando o aspecto da agência na jogabilidade, consideramos que a plataforma, que é simultaneamente uma ferramenta de autoria e um aplicativo, atua modulando as possibilidades semióticas do jogo, tanto no que se refere à interface quanto à agência e à interação. A ARIS permite a inserção de camadas de imagem sobre mapas, o que foi utilizado para indicar possíveis trajetos com uma imagem que representa trilhas conectando espaços, conforme se pode ver na Figura 2, abaixo. No mapa, o jogador vê imagens dos locais com os quais pode interagir e, quando se aproxima deles, ouve um sinal sonoro advindo do dispositivo móvel e verifica um marcador, na aba Nearby, que permite a interação com o local.

O que diferencia um jogo locativo dos demais jogos eletrônicos é a conexão intrínseca do espaço virtual ao espaço físico no qual a jogabilidade opera. A fim de cumprir as missões propostas pelo jogo na tela, os jogadores necessitam percorrer áreas do Jardim Botânico procurando por itens e realizando missões (quests) que lhe conferem pontos e propiciam a continuidade da experiência. Em Um dia no Jardim Botânico, os jogadores são convidados a coletar ferramentas de plantio como pá, regador, água, sementes e mudas "para ajudar a preservar as espécies do parque, tomando cuidado para não cair em armadilhas que lhes subtraiam pontos pelo caminho" (GOMES \& MARASCHIN, 2014, p. 1). Devem coletar estes itens e plantar em regiões correspondentes a cada espécie. 


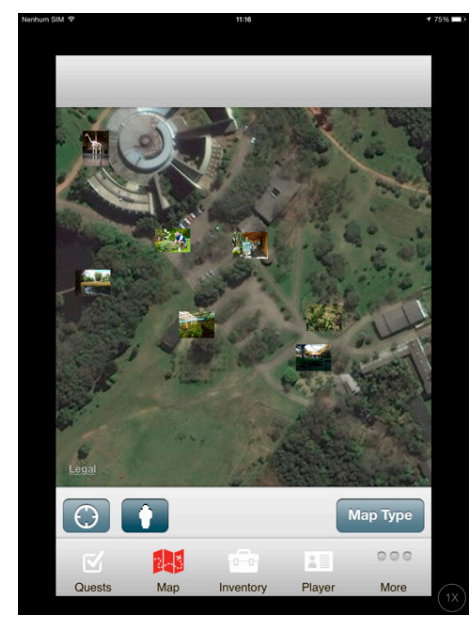

Figura 2 - Mapa indicando os locais a percorrer durante o jogo Fonte - Captura de tela pelas autoras

A localização do jogador é determinada pelo Serviço de Localização do sistema operacional iOS: o aplicativo mostra um mapa ou imagens de satélite com a localização aproximada do jogador, assinalada por um ponto azul. O jogo tem final aberto, pode continuar indefinidamente com o acúmulo de pontos, e permite um componente multijogador (BAUM; KROEFF \& MARASCHIN, 2014). Além de realizar as missões, o jogador pode, dentro do aplicativo, criar um perfil próprio com nome e foto, ler e executar tarefas a partir de QR codes, escrever notas, fazer gravações em áudio, registrar fotografias e vídeos, marcar pontos relevantes no mapa e compartilhar essas informações, produzindo conteúdos de maneira autoral, como pode ser visto nas telas capturadas do jogo nas Figuras 3, 4 e 5, abaixo.

Assim, o jogo é compreendido como um sistema semiótico complexo que prioriza os elementos lúdicos e interativos em detrimento de um conteúdo didático calcado em saberes declarativos (BAUM; KROEFF \& MARASCHIN, 2014). Recuperando a noção de multiletramentos, nos referimos a Gee (2003), que afirma que jogos eletrônicos constituem uma alfabetização digital por excelência, a qual compõe-se das seguintes habilidades: (a) decodificação, (b) compreensão e interpretação de significados e (c) produção de significados em cada domínio, o que intermedeia a ação de jogar. Contudo, para o autor, o aprendizado somente ocorre se 
o aprendiz for capaz de estabelecer, nesse sistema complexo constituído de partes interconectadas, modos como elas podem ser rearranjadas para produção de novos significados. Isso só é possível se o iniciante é introduzido não apenas no conteúdo de uma área do conhecimento, mas igualmente nas práticas sociais a ele ligadas (BAUM; KROEFF \& MARASCHIN, 2014), de modo que aprender é agir e experimentar o mundo, mediante multisemioses no contexto de um sistema complexo.

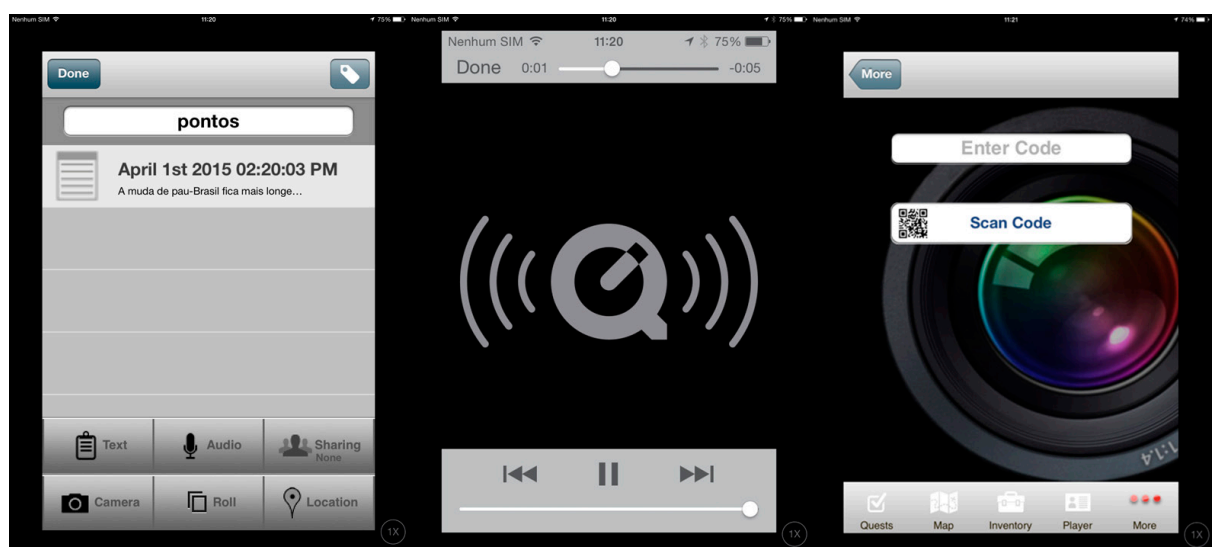

Figuras 3, 4 e 5 - Áreas do jogo em que o jogador pode produzir conteúdos próprios Fonte - Captura de tela pelas autoras

\section{Metodologia: etapas da pesquisa e categorias mobilizadas}

Buscando um caminho para a explicação das potencialidades dessas multisemioses aos letramentos na interface da jogabilidade, nos apoiamos na teoria semiótica de matriz francesa (GREIMAS \& COURTÊS, 2008) para empreendermos uma análise semiótica dos níveis fundamental, narrativo e discursivo da jogabilidade apresentada ao jogador na tela de interface do jogo, atentando para as características do design da jogabilidade na tela digital do dispositivo móvel. Tais níveis comprazem a análise de possíveis percursos gerativos de sentido (BARROS, 2005), os quais movimentam as ações dos jogadores.

A primeira etapa da pesquisa compreendeu jogar Um Dia no Jardim Botâncio no Parque Jardim Botânico de Porto Alegre com tablets, atentando 
: para elementos de sua jogabilidade na tela durante o jogo, enquanto se : percorria, a pé, os espaços físicos do terrítório.

A segunda etapa envolveu a captura das telas do jogo, realizada mediante o sistema de captura de telas embutido no iOS do Ipad 2, o qual permite que o usuário capture telas ao apertar simultaneamente os botões home e on/off. As telas capturadas ficam salvas no aplicativo de imagens do dispositivo móvel. As telas foram capturadas considerando as principais ações possibilitadas aos jogadores no decorrer do jogo, bem como seus mais importantes instrumentos e recursos.

$\mathrm{Na}$ terceira etapa da pesquisa, as categorias do percurso gerativo de sentido da teoria semiótica greimasiana, a saber, os níveis fundamental, narrativo e discursivo, foram analisadas nas telas capturadas, considerando-se também características da semiótica plástica, como o dispositivo topológico e as categorias eidéticas e cromáticas (GREIMAS, 2004), necessárias à análise de artefatos semiótico que sincretizam linguagens verbais e nãoverbais, como é o caso da interface de um jogo móvel de localização na tela digital.

\section{Análise semiótica da jogabilidade de Um Dia no JardimBotânico}

No exame do nível fundamental ou profundo do percurso gerativo de sentido, podemos situar os valores elementares do jogo, engendrados a partir de uma oposição lógico-semântica mínima. Constatamos que a oposição mínima circunda em torno da ação de preservar e sua negação, o não preservar, que resultaria na extinção ou redução de espécies do parque, conforme podemos ver na tela que apresenta a primeira missão do jogo ao jogador, na Figura 6, abaixo. As três fases ou missões do jogo acarretam em realizar ações de preservação, seja ajudando o jardineiro, aprendendo a plantar ou plantando mais sementes. Assim, verificamos que a semântica no jogo circula em torno dessa temática básica e suas correlações, estabelecida entre o preservar e o extinguir. 


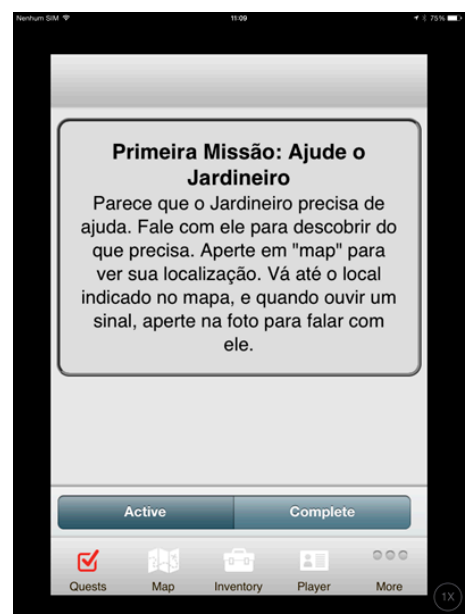

Figura 6 - Convite à missão de preservação através de ações práticas ligadas ao tema Fonte - Captura de tela pelas autoras

No nível narrativo, atentamos para os eventos e transformações previstos pelo jogo, identificando actantes, suas funções e modos de interação. Enquanto actantes da jogabilidade, temos primeiramente a figura projetada do próprio jogador pelo jogo, ator principal da narrativa. Ao jogador-herói cabe mergulhar em uma série de tarefas que lhe levarão na direção do alcance de seu objeto de valor, a preservação dos biomas do Jardim Botânico. Para isso, o jogador conta com a ajuda de adjuvantes, como o jardineiro, que lhe instrui sobre como operar no jogo mediante a missão de encontrar e lhe entregar uma pá, além de lhe fornecer regador e alertar sobre como conseguir a água necessária ao plantio. Outro adjuvante é o botânico, que entrega ao jogador a primeira semente, de orquídea. Jardineiro e botânico encaminham o jogador de um personagem adjuvante para o outro, na busca por estes itens digitais modais que ensejam à ação do jogador as modalidades de poder-fazer e saber-fazer, instituindo nesse um potencial sentimento modalizador de querer, pela recompensa advinda do alcance dos objetivos e de dever, dado pela missão primordial de preservar o parque para o bem do meio ambiente.

O ritmo é dado pelo próprio mover-se do jogador no espaço geográfico e no espaço híbrido do parque + tela do jogo. Conflitos do nível narrativo advêm das dificuldades do jogador no desenvolvimento 
: de estratégias de ação e na própria leitura do sistema semiótico do jogo, : que conjuga à tela digital a sinalização física do jardim, conforme se pode ver na Figura 7. Um oponente que adentra eventualmente a narrativa é o personagem lagarto, que somente aparece no jogo se o jogador passar por um local específico do parque, onde o lagarto somente lhe permite continuar a jogar se este lhe entregar um dos itens presentes em seu inventário. Nesse momento, o jogador deve atentar para o item a ser entregue que lhe causará menos prejuízo pois, se for um item essencial ao plantio, como o regador, o jogador terá de despender tempo novamente para pegar um novo regador com o jardineiro. A cada missão, o objeto de valor buscado, a preservação do parque, permanece. Mas a este objeto somam-se novos adjuvantes, como as mudas e sementes e as próprias áreas específicas do parque, que exemplificam a harmonia estética de sua preservação e reforçam a validade do objeto de valor.

O desfecho, porém, não é apresentado pelo jogo, visto seu caráter aberto. Não se sabe até que ponto a preservação do parque foi garantida. Mas há certo fechamento quando o jogador decide parar de jogar e averiguar sua pontuação, definindo se o jogo prossegue ou não, conforme pode ser visto na Figura 8. Esse caráter inacabado pode permitir o uso da criatividade e a geração de fechamentos interacionalmente negociados, quando dois jogadores decidem comparar sua pontuação no jogo, por exemplo. Outras formas de fechamento e evasão do jogo podem se dar quando jogadores perdem o interesse pela jogabilidade na tela digital e passam a interagir com os componentes do espaço físico do Jardim Botânico, como as tartarugas, peixes e cisnes do lago, as plantas e árvores de cada bioma ou as coleções do museu de ciências naturais, na frente do qual o jogador passa quando ajuda o jardineiro, na primeira missão, conforme proposto na tela caturada na Figura 6.

No nível discursivo, a investigação enfoca as disjunções e conjunções espaciotemporais e enunciativas presentes no artefato semiótico que, no caso de um jogo de localização, remetem tanto ao espaço físico do Jardim Botânico quanto ao espaço digital da tela, agregando-lhe dupla camada dimensional. A tela do dispositivo móvel desempenha o papel de enunciador, convidando o jogador enunciatário a manter-se no espaço bidimensional do jogo e a avançar nas missões percorrendo o espaço 
tridimensional do parque. Dêiticos como "este", em "Este é um jogo móvel locativo", na segunda tela do jardineiro, enunciam a referencialidade do jogo, estabelecendo sua coerência. Já o termo "agora”, que inicia os discursos verbais nas telas de abertura das missões 2 e 3 funciona no jogo como um indicador de sequencialidade, incitando o jogador a prosseguir de uma fase a outra. As conjunções e disjunções espaciotemporais são constantemente duplicadas, pela referência às ações a serem executadas na tela: "tap to continue", "leave conversation" e àquelas que pressupõem deslocamento físico pelo local: "vá até o depósito de sementes". Tais duplicações remetem a uma ancoragem discursiva que aproxima o jogador das enunciações do jogo, conferindo-lhe um efeito de realidade, e fá-lo escolher caminhos acionais para cumprir as tarefas propostas, reforçando este mesmo efeito de realidade pela interação com o espaço físico, enquanto mantém um aspecto ficcional pela narratividade do jogo, ausente do ambiente geográfico, mas presente na tela.

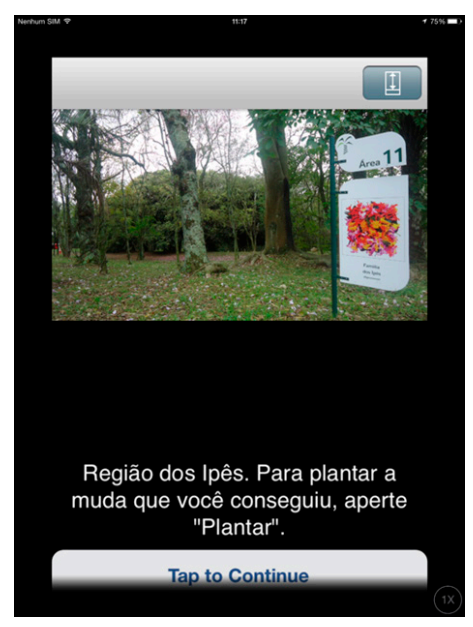

Figura 7 - Sinalização do parque

Fonte - Captura de tela pelas autoras

Figura 8 - Tela que pode ser acessada para checagem da pontuação Fonte - Captura de tela pelas autoras

Em todos os níveis de análise, levamos em conta o sincretismo de linguagens presentes nesta tela, a partir do dispositivo topológico e das categorias eidética e cromática advindas da semiótica plástica (GREIMAS, 
: 2004) nas tematizações e figurativizações identificáveis na interface do : jogo. Conforme podemos ver nas figuras 7 e 9, o jogo ilustra o caminho aos jogadores através de textos verbais somados a fotografias indicativas ou icônicas que remetem às próprias regiões do parque, como o depósito de sementes, o viveiro de orquídeas e o esqueleto da girafa, reforçando a tematização da preservação do meio ambiente que dá sentido ao jogo e ao próprio parque, como podemos ver na Figura 9.

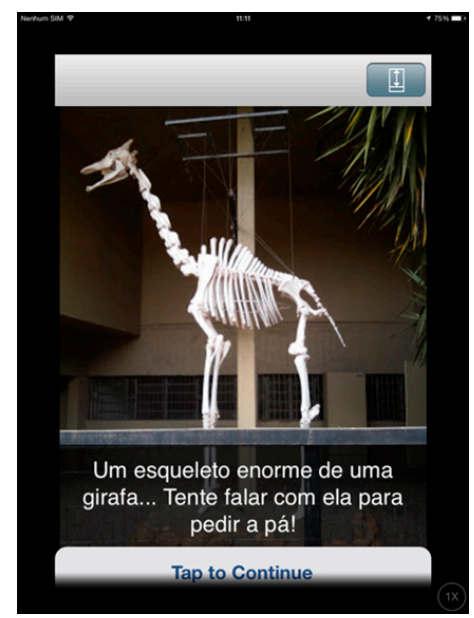

Figura 9 - Esqueleto da girafa

Fonte - Captura de tela pelas autoras

O não verbal se faz presente também no mapa, que instaura uma linguagem espacial possibilitadora da localização do jogador, personagens, objetos e áreas de execução das tarefas. A linguagem sonora também produz semioses no jogo através do som emitido pelo dispositivo móvel quando o jogador se aproxima de uma área importante à jogabilidade. No notebook do jogo, que permite anotações (conf. Figura 3), o jogador também pode usar de linguagem sonora para gravar áudios próprios ou do ambiente (conf. Figura 4). Ademais, pelo deslocamento no território, é possível que os jogadores encontrem trabalhadores e visitantes do parque e travem conversas com eles, além de precisarem ler e manejar o próprio sistema semiótico do Jardim.

Topologicamente, a tela do jogo divide-se entre imagens e mapas no espaço superior e textos e botões tendencialmente no espaço inferior, indicando que o exercício cognitivo do jogador leva-o a apreender uma 
síntese do estágio da narrativa e da jogabilidade através das imagens e mapas, para depois fornecer-lhe instruções e indicar os próximos passos pelo texto verbal e ícones, conforme pode-se ver na Figura 10, abaixo. Essas divisões topológicas também transparecem nas formas e cores do jogo, dado que ele possui uma moldura preta e linhas que separam os botões, imprimindo aos ícones cores e formas distintas, com o ícone selecionado na tela aparecendo em cor vermelha.

Essa hibridização das linguagens na jogabilidade do jogo remete aos multiletramentos, que pressupõem a produção de sentido entremeio linguagens distintas, compondo unidades de sentido a partir de sincretismos, bem como o caráter intuitivo da alfabetização digital, composta de habilidades de decodificação, compreensão e interpretação de significados e produção de sentidos em cada domínio, na lida com um sistema complexo que demanda constantes reorganizações por parte do jogador interlocutor.

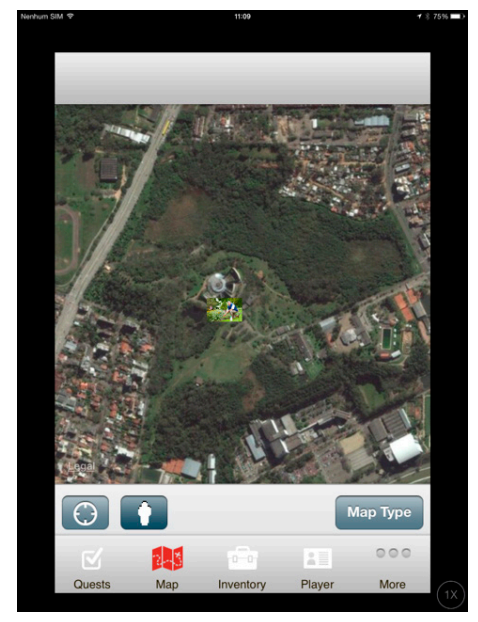

Figura 10 - Distribuição topológico-eidético-cromática da tela Fonte - Captura de tela pelas autoras

\section{CONSIDERAÇÕES: MULTILETRAMENTOS AGENCIADOS EM INTERFACE}

Considerando nossa pergunta norteadora: "Qual é o percurso gerativo de sentido da jogabilidade do jogo móvel de localização Um Dia no Jardim Botânico?”, chegamos à consideração de que tal percurso envolve estratégias multimodais de produção de semioses acionais, fazendo confluir 
a agência da interface na interação do jogo com o jogador, ao longo do : deslocamento entre o espaço físico-digital.

Uma vez que os jogos eletrônicos convidam os jogadores a uma série de desafios em uma relação causal (ROLLINGS \& ADAMS, 2003), os impelindo a desenvolver um conjunto de táticas (ASSIS, 2007) que envolvem, conforme a jogabilidade, interações entre jogador e ambiente do jogo, manipulação de regras e mecânicas, criação de estratégias e modulação de agenciamentos na interface semiótica da tela, constatamos que tais jogos agregam aos multiletramentos um componente acional, de movimentos criativos desenvolvidos em uma experiência projetada (SQUIRE, 2006) que pressupõe, no bojo das semioses, negociações e atividades conjuntas. Os multiletramentos nesse âmbito contribuem para uma inversão às ordens didáticas e para uma não linearização dos processos de aprendizagem, pois as instruções do jogo só adquirem consistência pela intervenção criativa do jogador.

No caso de um jogo móvel de localização, esse componente acional envolve intensa cinestesia, uma vez que o potencial dessa modalidade lúdica reside na articulação entre os ambientes físico e digital. Desse modo, quando nos referimos a multiletramentos nesse contexto, trata-se de produzir conexões em relação ao movimento dos jogadores, ao local e aos sistemas semióticos ali instaurados a fim de ampliar e potencializar as experiências e semioses possíveis.

Conforme Gavillon (2014, p. 78), "visto que é possível utilizar o jogo para disparar relações com o ambiente físico, pode-se conceber um jogo como uma porta de entrada para uma experiência de aprendizado imersa no próprio campo a ser aprendido”. Mais do que simular a interação com um campo do conhecimento, o jogo móvel de localização aproxima o jogador do espaço em si, ampliando as experiências nele, e articulando estratégias espaciais de ensino dentro de sua própria jogabilidade, o que não ocorreria em um jogo não locativo. Assim, experiências de aprendizagem com jogos locativos podem contribuir para a atenção aos aprendizes que não conseguem construir tantos conhecimentos por meios puramente visuais ou sonoros, mas que necessitam se movimentar e percorrer espaços.

Os estudantes, carentes de ações de locomoção, poderiam, em um jogo móvel de localização, gerar percursos de sentido incorporados a uma 
paisagem geográfica, produzindo significados atrelados a lógicas semânticas, narrativas e discursivas que lhes propiciassem aprendizagens que as salas de : aula não lhes fornecem.

\section{REFERÊNCIAS BIBLIOGRÁFICAS}

ARSENAULT, Dominic; PERRON, Bernard. In the Frame of the Magic Cycle: The Circle(s) of Gameplay. In: PERRON, Bernard; WOLF, Mark J. P. The video game theory reader 2. New York: Routledge, p. 109-132, 2009.

ASSIS, Jesus de Paula. Artes do Videogame: conceitos e técnicas. São Paulo: Alameda, 2007.

BARROS, Diana Luz Pessoa de. Teoria semiótica do texto. $4^{a}$ ed. São Paulo: Ática, 2005.

BAUM, Carlos A. S.; KROEFF, Renata F. S.; MARASCHIN, Cleci. Jogos locativos e aprendizagem corporal: notas preliminares. In: Anais eletrônicos do X Seminário Jogos Eletrônicos, Educação e Comunicação. UFBA, 2014. Disponível em: http://www.comunidadesvirtuais.pro.br/seminario-jogos/files/mod seminary submission/trabalho 78/trabalho.pdf. Acesso em: 13 jan. 2015.

BENFORD, Steve; MAGERKURTH, Carsten; LJUNGSTRAND, Peter. Bridging the physical and digital in pervasive gaming. Communications of the ACM, ACM, pp. 54-57, 2005.

BRITTTO, Luiz Percival L. Educação e Política: Sobre o Conceito de Letramento. In: BRITTO, Luiz Percival L. Contra o consenso: cultura escrita, educaşão e participação. Campinas: Mercado das Letras, 2003.

COPE, Bill; KALANTZIS, Mary. (orgs.). Multiliteracies: Literacy Learning and the Design

of Social Futures. New York: Routledge, 2006.

DIAS, Reinildes. Web Quests: Tecnologias, multiletramentos e a formação do professor de inglês para a era do ciberespaço. Revista Brasileira de Linguística Aplicada, Belo Horizonte, 2012. 
: FEIL, John H.; SCATTERGOOD, Marc. Beginning Game Level Design.

: Independence, KY: Course Technology Press, 2005.

GAGNON, David. ARIS: An open source platform for developing mobile learning experiences. Dissertação. Universidade de Wisconsin-Madison, 2010. Disponível em: http://arisgames.org/wp-content/uploads/2011/04/ ARIS-Gagnon-MS-Project.pdf. Acesso em: 14 dez. 2013.

GAVILLON, Poti Q. Videogames e politicas cognitivas. Dissertação (Mestrado em Psicologia Social e Institucional. Área de concentração: Redes SocioTécnicas, Cognição e Comunicação). Universidade Federal do Rio Grande do Sul, Porto Alegre, 2014.

GEE, James P. What video games have to teach us about learning and literacy. New York: PalGrave-McMillan, 2003.

GOMES, Raquel S. Textualidade sincrética como agir de linguagem situado em blogs produzidos por estudantes do Ensino Fundamental. Dissertação (Mestrado em Linguística Aplicada. Área de concentração: linguagem, interação, tecnologia) Universidade do Vale do Rio dos Sinos, São Leopoldo, 2013.

GOMES, Raquel S.; MARASCHIN, Cleci. Jogo locativo na educação integral:espacializações emergentes no linguajar pelo jogar. In: Anais eletrônicos do X Seminário Jogos Eletrônicos, Educação e Comunicação. UFBA, 2014. Disponível em: http://www.comunidadesvirtuais.pro.br/seminario-jogos/ files/mod_seminary_submission/trabalho_76/trabalho.pdf. Acesso em: 10 jan. 2015.

GREIMAS, Algirdas J.; COURTÉS, Joseph. Dicionário de Semiótica. São Paulo: Editora Contexto, 2008.

GREIMAS, Algirdas J. Semiótica figurativa e semiótica plástica. In: OLIVEIRA, A. C. (org.). Semiótica plástica. São Paulo: Hacker Editores, 2004. p. 75-96.

HEATON, Tom. A Circular Model of Gameplay In: Gamasutra.com, 2006. Disponível em http://www.gamasutra.com/view/feature/2569 /a circular_model_of_gameplay.php. Acesso em: 20 out. 2014. 
HOWLAND, Geoff. The focus of gameplay. Disponível em: http://www. lupinegames.com/articles/focus gameplay.html, 1999. Acesso em: 11 nov. 2014.

JUNG, Neiva M. Letramento: uma concepção de leitura e escrita como prática social. In: CORREA, Djane A.; SALEH, Pascoalina B. (Org.). Práticas de Letramento no Ensino: leitura, escrita e discurso. São Paulo: Parábola Editorial; Ponta Grossa: UEPG, 2007.

LATOUR, Bruno. Reagregando o Social: uma introdução à Teoria do Ator-Rede. Salvador/Bauru: Edufba/Edusc, 2012.

LEMOS, André. Jogos móveis locativos: Cibercultura, espaço urbano e mídia locativa. Revista USP, São Paulo, n.86, p. 54-65, junho/agosto, 2010.

LINDLEY, Craig A; The gameplay gestalt, narrative, and interactive storytelling. In: MÄYRÄ, Frans. (ed.) Proceedings of Computer Games and Digital Cultures Conference. Tampere, Finlândia: Tampere University Press, 2002. Disponível em: http://www.digra.org/dl/db/05164.54179. Acesso em: 03 mar. 2015.

MARASCHIN, Cleci. Oficinando em Rede: processos de aprendizagem e jogos locativos. Projeto de pesquisa. UFRGS, 2013.

MARCUSCHI, Luis A. Apresentação. ARAÚJO,J. C.; BIASI-RODRIGUES, B. (orgs.). In: Interação na Internet: novas formas de usar a linguagem. Rio de Janeiro: Lucerna, 2005.

MELLO, Vinicius D. L. Histórico e discussão do conceito de jogabilidade. Dissertação - Mestrado em Comunicação. Universidade do Estado do Rio de Janeiro, Rio de Janeiro, 2013.

ROJO, Roxane H. R. Pedagogia dos multiletramentos: diversidade cultural e de linguagens na escola. In: ROJO, Roxane H. R.; MOURA, Eduardo. (orgs.). Multiletramentos na escola. São Paulo: Parábola Editorial, 2012, p. 1132. 
: ROLLINGS, Andrew; ADAMS, Ernest. Andrew Rollings and Ernest Adams on : game design. San Francisco, CA: New Riders Publishing, 2003.

SICART, Miguel. Defining Game Mechanics. In: Game Studies, 2008. Disponível em: http://gamestudies.org/0802/articles/sicart. Acesso em: 03 mar. 2015.

SOARES, Magda. Letramento: um tema em três gêneros. São Paulo: Autêntica, 1999.

SOARES, Magda. Novas práticas de leitura e escrita: letramento na cibercultura. Educ. Soc., vol. 23, n. 81. Campinas, Dec. 2002. Disponível em: < http://www.scielo.br/pdf/es/v23n81/13935.pdf $>$. Acesso em: 18 abr. 2014.

SQUIRE, Kurt. From Content to Context: Videogames as Designed Experience. Educational Researcher, vol. 35, no. 8, p. 19-29, November, 2006.

TFOUNI, Leda V. Letramento e alfabetização. São Paulo: Cortez, 1995.

VANNUCCHI, Hélia; PRADO, Gilbertto. Discutindo o conceito de gameplay. Revista Texto Digital, vol. 5, n. 2. Universidade Federal de Santa Catarina, Florianópolis, 2009.

WALSH, Maureen. Multimodal Literacy: What Does It Mean for Classroom Practice? Australian

Journal of Language and Literacy, vol. 33, n. 3, p. 211-239, 2010. Disponível em: < http://www.alea.edu.au/documents/item/63>. Acesso em: 12 de out. 2014.

XAVIER, Antonio C. Letramento Digital e Ensino. Disponível em: < $\underline{\text { http:// }}$ www.ufpe.br/nehte/artigos/Letramento $\% 20$ digital $\% 20 \mathrm{e} \% 20$ ensino.pdf >. Acesso em: 18 abr. 2014. 